\title{
Reprodução de Meloidogyne enterolobii em olerícolas e plantas utilizadas na adubação verde ${ }^{1}$
}

\author{
Meloidogyne enterolobii reproduction on vegetable crops and plants used as green \\ manure
}

\author{
Juliana Magrinelli Osório Rosa ${ }^{2 *}$, Juliana Nogueira Westerich ${ }^{3}$ e Silvia Renata Siciliano Wilcken ${ }^{3}$
}

\begin{abstract}
RESUMO - Meloidogyne enterolobii é considerada uma espécie agressiva entre os nematoides das galhas. Nesse contexto, o objetivo do trabalho foi determinar o fator de reprodução de $M$. enterolobii, em 42 olerícolas e 18 plantas utilizadas na adubação verde. Os ensaios foram conduzidos em casa de vegetação. A infestação do solo foi realizada com 5.000 ovos e juvenis de segundo estádio de $M$. enterolobii/vaso. O delineamento experimental foi inteiramente casualizado com seis repetições por tratamento. Tomateiro 'Rutgers' foi utilizado como padrão de viabilidade do inóculo. As plantas consideradas resistentes foram alface 'Grand Rapids', cebolinhas 'Tokyo' e 'Nebuka', alho 'Poró Gigante', salsas 'Comum HT’e 'Graúda Portuguesa', cenouras 'Brasília', 'Brasília Irecê' e 'Planeta'; e todas as brássicas estudadas: couve-flor 'Teresópolis Gigante' e 'Piracicaba Precoce'; repolhos 'Chato de Quintal' e 'Coração de Boi'; brócolis 'Piracicaba', 'Brasília', 'Santana', 'Cabeça', 'Bruxelas' e “Tronchuda Portuguesa'. Os adubos verdes azevém, Crotalaria breviflora, C. juncea, C. spectabilis, C. mucronata, C. ochroleuca, Dolichos lablab, Pennisetum glaucum, Mucuna deeringiana, M. cinereum, M. aterrima e Raphanus sativus também foram resistentes. Essas plantas constituem opção viável para a rotação de culturas em áreas infestadas com M. enterolobii.
\end{abstract}

Palavras-chave: Nematoide das galhas. Olericultura. Adubação verde.

\begin{abstract}
Meloidogyne enterolobii is considered to be an aggressive root-knot species. The goal of this work was determine the $M$. enterolobii reproduction factor on 42 vegetable crops and on 18 plants used as green manure. The experiments were carried in a greenhouse. The substrate inoculation was made with 5,000 eggs and second stage juveniles of $M$. enterolobii/plot. The experimental delineations were entirely randomized, with six replications. Resistance was found in 'Brasília', 'Brasília Irecê' and 'Planeta' carrot, 'Grand Rapids' lettuce; 'Tokyo' and 'Nebuka' chive; 'Poró Gigante' leeks; 'Comum HT' and 'Graúda Portuguesa' parsley and all brassicas plants studied: 'Teresópolis Gigante' and 'Piracicaba Precoce' cauliflower; 'Chato de Quintal' and 'Coração de Boi' cabbage; 'Piracicaba', 'Brasília', 'Santana' and 'Cabeça' broccoli and 'Bruxelas' and 'Tronchuda Portuguesa' cole. Lollium multiflorum, Crotalaria breviflora, C. juncea, C. spectabilis, C. mucronata, C. ochroleuca, Dolichos lablab, Pennisetum glaucum, Mucuna deeringiana, M. cinereum, M. aterrima and Raphanus sativus green manures were resistant. These plants are viable options to crop rotation in $M$. enterolobii infested areas.
\end{abstract}

Key words: Root-knot nematodes. Horticultural. Green manure.

\footnotetext{
DOI: $10.5935 / 1806-6690.20150071$

* Autor para correspondência

${ }^{1}$ Recebido para publicação em 10/04/2014; aprovado em 05/08/2015

Parte da Tese de Doutorado da primeira autora apresentada ao Programa de Pós-Graduação em Agronomia: Proteção Vegetal da Universidade Estadual Paulista "Júlio de Mesquita Filho"

${ }^{2}$ Departamento de Proteção Vegetal - Área de Nematologia Agrícola, Faculdade de Ciências Agronômicas, Universidade Estadual Júlio de Mesquita Filho, Brasil, julianamagrinelli@ hotmail.com

${ }^{3}$ Departamento de Proteção Vegetal - Área de Nematologia Agrícola, Faculdade de Ciências Agronômicas, Universidade Estadual Júlio de Mesquita Filho, Brasil, juwesterich@hotmail.com, srenata@fca.unesp.br
} 


\section{INTRODUÇÃO}

A espécie Meloidogyne enterolobii (YANG; EISENBACK, 1983) foi descrita a partir do parasitismo em raízes de Enterolobium contortisiliquum (Vell.), na China. Após alguns estudos (TIGANO et al., 2010; XU et al., 2004) foi verificado que $M$. enterolobii e $M$. mayaguensis (RAMMAH; HIRSCHMANN, 1988) que haviam sido relatadas em raízes de Solanum melongena, tratava-se da mesma espécie, resultando numa sinonímia entre esses dois nematoides. A alta taxa de reprodução e a ampla gama de hospedeiros evidencia a agressividade da espécie, capaz de superar fontes de resistência a outras meloidoginoses como $M$. incognita, $M$. javanica e M. arenaria (BRITO et al., 2007; CANTU et al., 2009; KIEWNICK; DESSIMOZ; FRANCK, 2009).

Desde 1991, há registros importantes dos danos provocados pela espécie $M$. enterolobii, relatados em materiais vegetais provenientes da Ásia, América do Sul e África; em estufas de tomate e pepino, na Suíça; na Ásia, nos países da China (Hainan, Guangdong) e no Vietnã. $\mathrm{Na}$ América do Norte (Flórida-EUA) foi relatada pela primeira vez em 2002, em plantas ornamentais, em campo comercial de tomate e em viveiro de frutas tropicais. Há registros também na América Central e Caribe, em Cuba, Martinica, Porto Rico, Trinidad e Tobago, e atingindo o Continente da América do Sul, no Brasil e na Venezuela, de acordo com European and Mediterranean Plant Protection Organization (2008).

No Brasil, essa espécie foi registrada em 2001, causando prejuízos em pomares de goiaba nos estados de Pernambuco e Bahia, naquele momento, designada como M. mayaguensis (CARNEIRO et al., 2001). M. enterolobii tem sido responsável por grandes danos em todo o país, destacando-se os prejuízos ocorridos em frutas tropicais e hortaliças. Assim, o conhecimento de seus potenciais hospedeiros éessencial para adoção de medidas preventivas e de controle, visto que sua gama de hospedeiro ainda é pouco conhecida, com exceção de algumas plantas tais como goiaba, milho, pepino, abóbora etc (MIRANDA et al., 2011; ROSA; WESTERICH; WILCKEN, 2012; WILCKEN et al., 2013). Diante do exposto, a espécie referida é tida como uma das mais agressivas dentre as que contemplam o gênero Meloidogyne (RODRIGUEZ; GÓMEZ; PETEIRA, 2007).

Segundo Silva (2010), diversas plantas de adubo verde apresentam mecanismos de resistência que impedem a reprodução dos nematoides fitoparasitos, reduzindo a sua população no solo, destacando-se as leguminosas do gênero Crotalaria, que apresentam níveis eficientes no controle de M. incognita, M. javanica, Pratylenchus brachyurus, P. zeae e Rotylenchus reniformis. Contudo, existem discordâncias na literatura sobre a eficiência do controle desses nematoides, principalmente em relação a C. juncea (GUIMARÃES; MOURA; PEDROSA, 2003). Alguns trabalhos demonstram a multiplicação das espécies de Meloidogyne nessas plantas, entre eles os mais recentes foram Guimarães, Moura e Pedrosa (2003), Inomoto et al. (2006), Moraes et al. (2006), Charchar et al. (2007) e Rosa, Westerich e Wilcken (2013). Ademais, ainda é escasso o conhecimento sobre o comportamento dessas espécies vegetais em relação ao parasitismo de M. enterolobii.

Devido ao exposto, a pesquisa teve como objetivo avaliar a reprodução de $M$. enterolobii em diferentes olerícolas e em plantas utilizadas na adubação verde, como meta para viabilizar a indicação de uma ou mais espécies vegetais resistentes ao controle, em áreas infestadas com essa espécie de nematoide.

\section{MATERIAL E MÉTODOS}

A presente pesquisa foi desenvolvida no setor de Defesa Fitossanitária do Departamento de Proteção Vegetal da Faculdade de Ciências Agronômicas/UNESP - Câmpus de Botucatu, no estado de São Paulo, Brasil. Os ensaios foram conduzidos em casa de vegetação climatizada com temperatura ajustada a $25 \pm 2{ }^{\circ} \mathrm{C}$. Foram estudadas 42 cultivares de olerícolas, divididos em cinco ensaios ( 1 a 5 - agrupadas em plantas condimentares/tomate, tuberosas, brássicas, alfaces e pimentas/pimentões) e 18 espécies de plantas de adubo verde, em três ensaios (6 a 8) para obtenção do fator de reprodução de $M$. enterolobii. Além disso, dois ensaios foram conduzidos para confirmação dos resultados nos ensaios de plantas de adubação verde, devido à variabilidade genética dessas sementes.

As olerícolas avaliadas foram sete plantas utilizadas como condimentares/tomate. Dentre elas: alho 'Poró gigante', cebolinhas (todo ano 'Nebuka' (Tiunegui) e 'Tokyo' (Futonegui)), coentro 'Verdão', salsas ('Comum HT' e graúda 'Portuguesa') e tomate 'Block'; nove tuberosas: beterrabas ('Chata do Egito', 'Early Wonder' e 'Maravilha'), cenouras ('Brasília', 'Brasília Irecê' e 'Planeta') e rabanetes ('Comprido Branco', 'Comprido Vermelho' e 'Redondo Vermelho'); dez cultivares de brássicas: brócolis ('Brasília', 'Cabeça', 'Piracicaba', 'Santana', 'Tronchuda 'Portuguesa'), couve de 'Bruxelas', couve flores ('Piracicaba Precoce'e 'Teresópolis Gigante') e repolhos ('Chato de Quintal' e 'Coração de Boi'); cinco cultivares de alface ('Aurélia', 'Grand Rapids', 'Karla', 'Regina HT' e 'Roxa'); onze de Capsicum spp.: pimentas ('Amarela Comprida', 'Cambuci', 'Dedo de Moça', 'Doce Italiana', 'Jalapeño M' e 'Malagueta'), pimentões ('Casca Dura Ikeda', 'Dagmar' e 'Magna Super') e dois porta enxertos para pimentão ('AF 8253' e 'Silver'); e dezoito 
plantas utilizadas como adubo verde: azevém, crotalárias (Crotalaria breviflora, C. juncea, C. mucronata, $C$. ochroleuca, C. spectabilis), ervilhaca, feijão de porco, girassois ('Catissol' e 'IAC Uruguai'), guandus ('Fava larga' e guandu anão cv. 'Iapar 43'), labe-labe, milheto, mucunas (anã, cinza e preta) e nabo forrageiro.

As plantas de olerícolas foram semeadas em bandeja de poliestireno expandido (128 células) contendo substrato Plantmax ${ }^{\circledR}$. As mudas com $10 \mathrm{~cm}$ de altura foram transplantadas para vasos de polietileno com capacidade de 2 litros (L) contendo substrato autoclavado na proporção 1:2:1 (solo: areia: matéria orgânica - esterco bovino), em seus respectivos tratamentos.

Para a semeadura das plantas de adubação verde foram utilizadas três sementes em vasos, contendo o mesmo substrato anterior e, após a emergência das plântulas, foi realizado o desbaste das mesmas, deixando uma planta por vaso. Com exceção do ensaio 8 , instalado apenas em vasos de 2,0 L, os demais ensaios (6 e 7) foram conduzidos primeiramente em vasos de 2,0 L e em seguida em recipientes de polietileno de $500 \mathrm{~mL}$ para confirmação dos resultados.

A população de $M$. enterolobii foi isolada a partir de raízes do porta enxerto para pimentão 'Silver', coletadas no município de Campos Novos Paulista (SP). Populações puras do nematoide foram mantidas em casa de vegetação em plantas de tomateiros 'Rutgers'. Os ovos de $M$. enterolobii foram extraídos utilizando-se a metodologia sugerida por Coolen e D’Herde (1972), consistindo no trituramento das raízes em liquidificador, com a utilização de hipoclorito de sódio a $0,5 \%$ e em seguida sendo vertido em conjunto de peneiras de malhas 20; 60 e 500 Mesh (abertura de 0,85; 0,250 e 0,025 $\mathrm{mm}$, respectivamente), e posterior centrifugação, recolhendo o material retido na peneira de 500 Mesh, para quantificação dos ovos em lâmina de Peters, sob microscópio óptico.

Dois dias após o estabelecimento da muda, a mesma foi inoculada com aproximadamente 5.000 ovos e juvenis de segundo estádio $\left(\mathrm{J}_{2}\right)$ de $M$. enterolobii (População inicial - Pi) para cada tratamento, adicionando $2 \mathrm{~mL}$ de suspensão de ovos em dois orifícios equidistantes com 3,0 cm de profundidade na rizosfera de cada planta. Tomateiros 'Rutgers' foram utilizados para confirmação de viabilidade dos ovos de $M$. enterolobii. Todos os ensaios foram dispostos em um delineamento experimental inteiramente casualizado, com seis repetições.

A avaliação procedeu-se após 60 dias da inoculação (DAI), em que $250 \mathrm{~mL}$ de solo foi processado segundo Jenkins (1964), que consiste em flotação, peneiramento e centrifugação. Já os sistemas radiculares foram cuidadosamente lavados, pesados e corados com solução de Floxina B 0,005\%, para contagem de galhas e massas de ovos presentes nas raízes, obtendo-se assim, o índice de galhas (IG) e o índice de massas de ovos (IMO), proposto por Taylor e Sasser (1978), em que $0=$ sem galhas ou massas de ovos; $1=1$ a 2 galhas ou massas de ovos; $2=3$ a 10 galhas ou massas de ovos; $3=11$ a 30 galhas ou massas de ovos; $4=31$ a 100 galhas ou massas de ovos e $5=$ mais de 100 galhas ou massas de ovos por raiz. Em seguida, os sistemas radiculares foram processados segundo o método de Coolen e D'Herde (1972), acima citado. A quantificação do número final de ovos e juvenis recém-eclodidos na suspensão final foi realizada com lâmina de Peters, sob microscópio óptico. Os valores de população final (Pf) foram utilizados para calcular o fator de reprodução (FR) [FR=Pf/Pi], conforme Oostenbrink (1966), em que as plantas com FR $=0$ são consideradas imunes, FR $<1$ consideradas resistentes e FR $>1$ consideradas suscetíveis.

Os resultados obtidos de Pf e o FR foram transformados em $\sqrt{ } \mathrm{x}+0,5$ e submetidos à análise de variância, sendo as médias comparadas pelo teste de Tukey a 5\% de probabilidade, utilizando o programa estatístico Sisvar (FERREIRA, 2011).

\section{RESULTADOS E DISCUSSÃO}

\section{Ensaio com plantas de olerícolas}

Entre as 42 plantas de olerícolas estudadas, 23 foram consideradas suscetíveis à espécie $M$. enterolobii, sendo possível inferir que essa espécie de nematoide prefere alguns grupos de plantas, principalmente algumas solanáceas, tais como pimentão, pimenta e tomate, concordando com Cantu et al. (2009) que observaram alta reprodução nos porta enxertos de tomate Guardião, Helper-M, Anchor-T, Dr. K, Kagemuscha, TMA 809, Magnet e He-Man.

Entre as plantas condimentares avaliadas no ensaio 1, apenas a cultivar de coentro 'Verdão' foi suscetível a espécie $M$. enterolobii, apesar do valor de FR não diferir estatisticamente das demais plantas condimentares (Tabela 1). A cultivar de tomate 'Block', que foi incluída nesse ensaio, e portadora do gene $\mathrm{Mi}$, que confere resistência a outras meloidoginoses como $M$. arenaria, $M$. incognita e M. javanica foi à única planta que permitiu alto nível de reprodução de $M$. enterolobii. Rosa, Westerich, Wilcken, 2014 verificaram que os híbridos de tomate Cordillera, Ellen, Fascínio, Laura, Marguerita, Nícolas e Sanni, portadores do gene $M i$, também foram suscetíveis a $M$. enterolobii. Este fato ocorreu devido à alta virulência de M. enterolobii. Assim, essa espécie é capaz de vencer a resistência conferida pelo gene $M i$, tornando as plantas suscetíveis a $M$. enterolobii. Essa afirmativa está de 
acordo com observações em estudos anteriores que comprovaram essa incapacidade genética do gene $\mathrm{Mi}$ a M. enterolobii (CARNEIRO et al., 2006; CANTU et al., 2009; KIEWNICK; DESSIMOZ; FRANCK, 2009; MELO et al., 2011; WESTERICH; ROSA; WILCKEN, 2011; ROSA; WESTERICH;WILCKEN, 2014).

Tabela 1 - Índice de galhas (IG), índice de massa de ovos (IMO), população final (Pf) e fatores de reprodução (FR) de $M$. enterolobii em olerícolas

\begin{tabular}{|c|c|c|c|c|c|}
\hline Ensaio 1 - Condimentares/tomate & $\mathrm{IG}$ & IMO & Pf & FR & Reação* \\
\hline Cebolinha Todo Ano 'Tokyo’ (Futonegui) & 0,0 & 0,0 & $124 \mathrm{a}$ & $0,02 \mathrm{a}$ & $\mathrm{R}$ \\
\hline Cebolinha Todo Ano 'Nebuka' (Tiunegui) & 0,0 & 0,0 & $377 \mathrm{a}$ & $0,08 \mathrm{a}$ & $\mathrm{R}$ \\
\hline Alho 'Poró Gigante' & 0,0 & 0,0 & $431 \mathrm{a}$ & $0,09 \mathrm{a}$ & $\mathrm{R}$ \\
\hline Salsa 'Comum HT' & 2,8 & 2,0 & $1.177 \mathrm{a}$ & $0,24 \mathrm{a}$ & $\mathrm{R}$ \\
\hline Salsa Graúda 'Portuguesa' & 3,7 & 2,0 & $1.925 \mathrm{a}$ & $0,39 \mathrm{a}$ & $\mathrm{R}$ \\
\hline Coentro 'Verdão' & 3,2 & 3,2 & $5.665 \mathrm{a}$ & $1,13 \mathrm{a}$ & $\mathrm{S}$ \\
\hline Tomate 'Block' & 5,0 & 4,8 & $49.036 \mathrm{~b}$ & $9,81 \mathrm{~b}$ & $\mathrm{~S}$ \\
\hline $\mathrm{CV}(\%)$ & & & 65,26 & 41,35 & \\
\hline 'Rutgers' & 5,0 & 5,0 & 241.053 & 48,21 & \\
\hline \multicolumn{6}{|l|}{ Ensaio 2 - Tuberosas } \\
\hline Cenoura 'Brasília' & 1,2 & 0,2 & $267 \mathrm{a}$ & $0,05 \mathrm{a}$ & $\mathrm{R}$ \\
\hline Cenoura 'Brasília Irecê' & 0,3 & 0,0 & $291 \mathrm{a}$ & $0,06 \mathrm{a}$ & $\mathrm{R}$ \\
\hline Cenoura 'Planeta' & 0,5 & 0,2 & $409 \mathrm{a}$ & $0,08 \mathrm{a}$ & $\mathrm{R}$ \\
\hline Rabanete 'Comprido Vermelho' & 2,3 & 1,3 & $10.608 \mathrm{~b}$ & $2,12 \mathrm{bc}$ & $\mathrm{S}$ \\
\hline Rabanete 'Redondo Vermelho' & 2,3 & 2,0 & $11.401 \mathrm{~b}$ & $2,28 \mathrm{bc}$ & S \\
\hline Rabanete 'Comprido Branco' & 2,5 & 1,8 & $12.487 \mathrm{~b}$ & $2,50 \mathrm{c}$ & $\mathrm{S}$ \\
\hline Beterraba 'Maravilha' & 5,0 & $*$ & $25.027 \mathrm{c}$ & $5,01 \mathrm{~d}$ & $\mathrm{~S}$ \\
\hline Beterraba 'Chata do Egito' & 5,0 & $*$ & $35.443 \mathrm{~d}$ & $7,09 \mathrm{e}$ & S \\
\hline Beterraba 'Early Wonder' & 5,0 & $*$ & $43.341 \mathrm{e}$ & $8,67 \mathrm{f}$ & S \\
\hline $\mathrm{CV}(\%)$ & & & 6,04 & 3,36 & \\
\hline 'Rutgers' & 5,0 & 5,0 & 166.427 & 33,29 & \\
\hline \multicolumn{6}{|l|}{ Ensaio 3 - Brássicas } \\
\hline Couve Flor 'Teresópolis Gigante' & 0,8 & 0,0 & $0 \mathrm{a}$ & $0,00 \mathrm{a}$ & $\mathrm{I}$ \\
\hline Couve Flor 'Piracicaba Precoce' & 1,3 & 0,0 & $0 \mathrm{a}$ & $0,00 \mathrm{a}$ & I \\
\hline Repolho 'Chato de Quintal' & 1,7 & 0,0 & $0 \mathrm{a}$ & $0,00 \mathrm{a}$ & I \\
\hline Couve Brócolo Ramoso 'Piracicaba' & 2,7 & 0,0 & $195 \mathrm{a}$ & $0,04 \mathrm{a}$ & $\mathrm{R}$ \\
\hline Couve de 'Bruxelas' & 0,5 & 0,2 & $100 \mathrm{a}$ & $0,02 \mathrm{a}$ & $\mathrm{R}$ \\
\hline Couve 'Tronchuda Portuguesa' & 1,8 & 0,2 & $120 \mathrm{a}$ & $0,02 \mathrm{a}$ & $\mathrm{R}$ \\
\hline Couve Brócolo Ramoso 'Brasília' & 0,0 & 0,0 & $126 \mathrm{a}$ & $0,03 \mathrm{a}$ & $\mathrm{R}$ \\
\hline Couve Brócoli Ramoso 'Santana' & 2,0 & 0,0 & $183 \mathrm{a}$ & $0,04 \mathrm{a}$ & $\mathrm{R}$ \\
\hline Brócolis de 'Cabeça' & 2,3 & 1,8 & $1.205 \mathrm{~b}$ & $0,24 \mathrm{~b}$ & $\mathrm{R}$ \\
\hline Repolho 'Coração de Boi' & 2,8 & 2,2 & $2.704 \mathrm{c}$ & $0,54 \mathrm{c}$ & $\mathrm{R}$ \\
\hline $\mathrm{CV}(\%)$ & & & 56,02 & 5,65 & \\
\hline 'Rutgers' & 5,0 & 5,0 & 202.655 & 40,53 & \\
\hline
\end{tabular}

${ }^{1}$ Médias seguidas pela mesma letra minúscula na coluna não diferem entre si, pelo teste de Tukey, a 0,5 \% de probabilidade. Dados transformados em $\sqrt{ } \mathrm{x}+0,5 .{ }^{*} \mathrm{I}=$ Imune, $\mathrm{S}=$ Suscetível, $\mathrm{R}=$ Resistente 
Todas as cultivares de cenoura, 'Brasília', 'Brasília Irecê' e 'Planeta' foram resistentes a essa espécie de nematoide, com valor de FR igual a 0,05; 0,06 e 0,08 , respectivamente (Tabela 1). Os valores inferiores a 0,1 caracterizam alto grau de resistência proporcionado por essas cultivares a $M$. enterolobii. A resistência da cultivar 'Brasília Irecê' a $M$. enterolobii também foi verificada em estudo realizado por Bitencourt e Silva (2010). Contudo, quando as mesmas cultivares foram submetidas à infestação com M. javanica, comportaram-se como suscetíveis, apresentando FR mais baixos para 'Brasília Irecê' $(1,04)$ e 'Brasília' (2,49), e FR elevado para a cultivar 'Planeta' $(9,52)$ (ROSA; WESTERICH; WILCKEN, 2013). Em estudo realizado por Charchar et al. (2007) foi registrado nas cenouras 'Alvorada' e 'Brasília', grau de resistência moderada entre 60 e $70 \%$ às espécies de Meloidogyne, fato este que poderia contribuir para uma economia de 30 a $40 \%$ no custo de aquisição de defensivos químicos.
Dentre as nove plantas tuberosas estudadas no ensaio 2, seis foram classificados como suscetíveis a $M$. enterolobii, com FR > 1 (rabanete 'Comprido Vermelho', rabanete 'Redondo Vermelho', rabanete 'Comprido Branco', beterraba 'Maravilha', beterraba 'Chata do Egito' e beterraba 'Early Wonder'). A beterraba 'Early Wonder' foi a que mais aumentou a população de $M$. enterolobii, sendo observadas deformações como o empipocamento desses tubérculos. Ademais, as cultivares de beterraba apresentaram maior IG, dentro da escala de nota proposta por Taylor e Sasser (1978), entretanto, apenas foi possível a visualização de inúmeras galhas, não sendo realizada a contagem do número de massas de ovos que se mostraram conspícuas. Além disso, a coloração presente nesses tubérculos contribuiu para a difícil visualização de alguma massa de ovo que tenha extravasado o córtex celular. Bifurcação foi observada apenas no rabanete 'Comprido Branco’ (Figura 1). Os sintomas exibidos nesse grupo de

Figura 1 - Sintomas de galhas (coloridas com Floxina B) provocadas por M. enterolobii em girassol cv. 'IAC Uruguai' (A), guandu cv. 'Fava Larga' (B), galhas em beterraba 'Early Wonder' (C), bifurcação em rabanete 'Comprido Branco' (D) e empipocamento em rabanete 'Redondo Vermelho' (E)

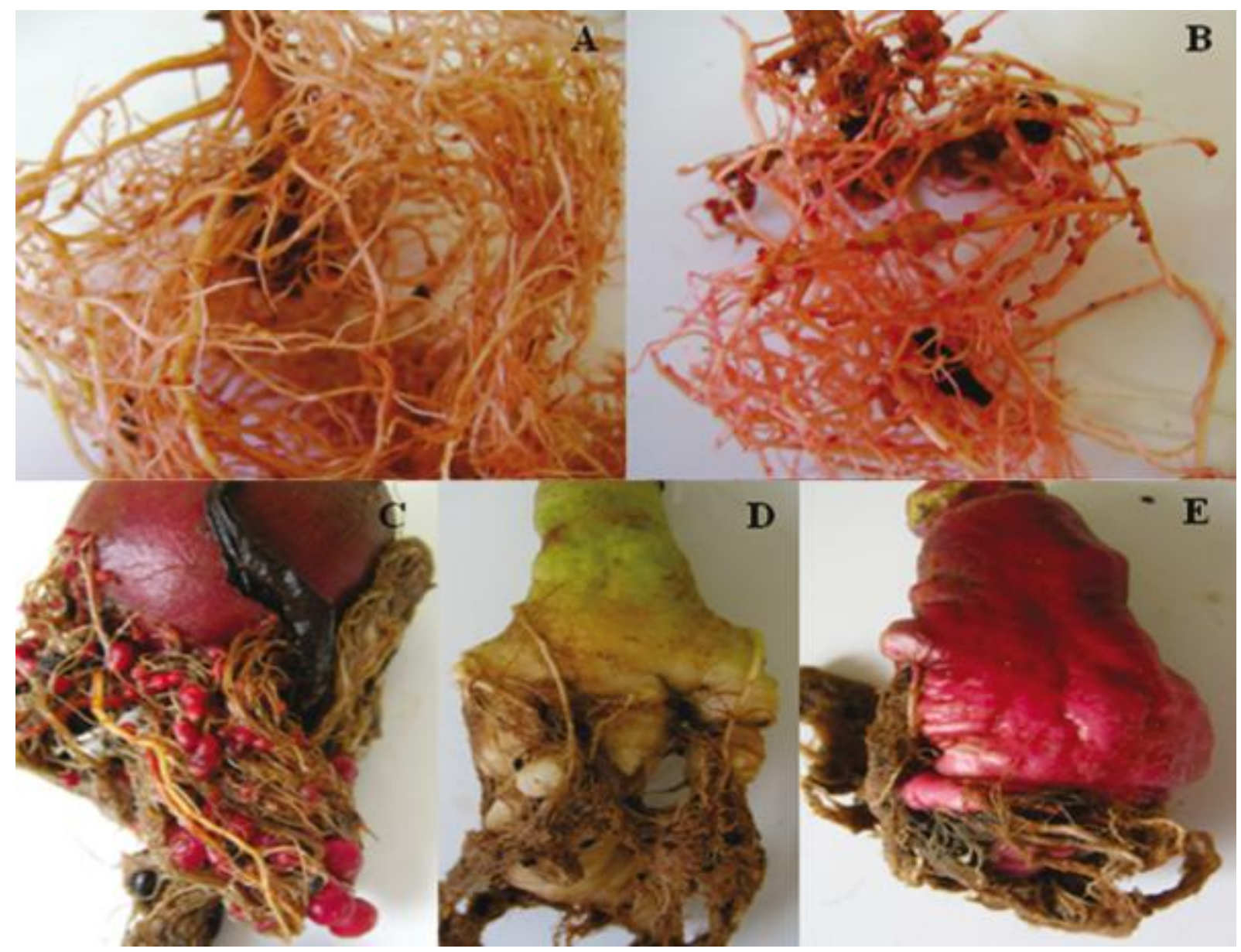


plantas atacadas por M. enterolobii provoca a perda desses produtos para o consumo, uma vez que ao estabelecer o sítio de alimentação, o nematoide irá provocar uma desorganização celular, resultando em deformação dos tubérculos, tornando-os inutilizáveis para a venda no comércio. Os sintomas mencionados também foram registrados por Rosa, Westerich e Wilcken (2013) nas mesmas cultivares infestadas com $M$. javanica, entretanto com superior severidade da apresentada pela espécie $M$. javanica.

O comportamento de resistência com baixo fator de reprodução também foi observado em todas as brássicas estudadas (ensaio 3). A ausência de reprodução do nematoide foi constatada principalmente em duas cultivares de couve-flor: 'Piracicaba Precoce' e 'Teresópolis Gigante' e em uma cultivar de repolho 'Chato de Quintal', que apresentaram FR igual a zero.
A suscetibilidade em cultivares de brócolis e repolho a $M$. enterolobii e a resistência em beterraba e salsa a essa espécie de nematoide foram observados em estudo realizado por Rodriguez, Sanchez e Rowe (2003), evidenciando que mesmo em cultivares distintas ao estudo, ocorreram comportamentos semelhantes de reação por essas plantas.

Resposta suscetível a M. enterolobii prevaleceu nos ensaios 4 e 5 (Tabela 2). Dentre as cinco cultivares de alface, apenas 'Grand Rapids' não permitiu o aumento da população de nematoides com $\mathrm{FR}=0,78$. Provavelmente, o gene de resistência dessa cultivar também proporciona resistência a $M$. enterolobii, diferentemente do que ocorre no caso de cultivares portadores do gene $\mathrm{Mi}$. Outras cultivares de alface, como por exemplo, 'Júlia', 'Hortência', 'Grand Rapids', 'Verônica' e 'Babá de Verão' também se mostraram com alta resistência (MELO et al.,

Tabela 2 - Índice de galhas (IG), índice de massa de ovos (IMO), população final (Pf) e fatores de reprodução (FR) de M. enterolobii em alface, pimenta e pimentão

\begin{tabular}{|c|c|c|c|c|c|}
\hline & IG & IMO & $\mathrm{Pf}$ & FR & Reação* \\
\hline \multicolumn{6}{|l|}{ Ensaio 4 - Alface } \\
\hline 'Grand Rapids' & 3,8 & 2,5 & $3.910 \mathrm{a}$ & $0,78 \mathrm{a}$ & $\mathrm{R}$ \\
\hline 'Aurélia' & 5,0 & 3,0 & $9.860 \mathrm{a}$ & $1,97 \mathrm{a}$ & $S$ \\
\hline 'Regina HT' & 5,0 & 3,5 & $10.345 \mathrm{a}$ & $2,07 \mathrm{a}$ & $S$ \\
\hline 'Karla' & 5,0 & 3,3 & $32.313 \mathrm{~b}$ & $6,46 \mathrm{~b}$ & $\mathrm{~S}$ \\
\hline 'Roxa' & 5,0 & 4,7 & $69.668 \mathrm{c}$ & $13,93 \mathrm{c}$ & S \\
\hline $\mathrm{CV}(\%)$ & & & 23,01 & 20,39 & \\
\hline 'Rutgers' & 5,0 & 5,0 & 266.877 & 53,38 & \\
\hline \multicolumn{6}{|c|}{ Ensaio 05 - Pimenta e Pimentão } \\
\hline Pimenta 'Dedo de Moça' & 3,0 & 2,7 & $7.116 \mathrm{a}$ & $1,42 \mathrm{a}$ & $\mathrm{S}$ \\
\hline Pimenta 'Malagueta' & 3,5 & 3,2 & $25.958 \mathrm{ab}$ & $5,19 a b$ & $S$ \\
\hline Pimenta 'Doce Italiana' & 5,0 & 4,2 & $29.215 \mathrm{abc}$ & $5,84 \mathrm{abc}$ & $S$ \\
\hline Pimenta 'Jalapeño M’ & 4,5 & 4,0 & $33.653 \mathrm{abc}$ & $6,73 \mathrm{abc}$ & $S$ \\
\hline Pimentão ‘Dagmar’ & 5,0 & 5,0 & $57.567 \mathrm{bcd}$ & $11,51 \mathrm{bcd}$ & $S$ \\
\hline Pimenta 'Amarela Comprida' & 5,0 & 4,8 & $75.710 \mathrm{bcd}$ & $15,14 \mathrm{bcd}$ & $S$ \\
\hline Pimentão 'Casca Dura Ikeda' & 4,8 & 4,7 & $87.152 \mathrm{bcd}$ & $17,43 \mathrm{bcd}$ & $S$ \\
\hline Pimentão 'Silver' & 3,7 & 3,7 & $89.628 \mathrm{bcd}$ & $17,93 \mathrm{bcd}$ & $S$ \\
\hline Pimentão 'Magna Super' & 4,5 & 4,3 & $101.682 \mathrm{~cd}$ & $20,34 \mathrm{~cd}$ & S \\
\hline Pimenta 'Cambuci’ & 4,5 & 4,5 & $112.417 \mathrm{~d}$ & $22,48 \mathrm{~d}$ & $S$ \\
\hline Pimentão 'AF 8253' & 5,0 & 5,0 & $239.688 \mathrm{e}$ & $47,94 \mathrm{e}$ & S \\
\hline $\mathrm{CV}(\%)$ & & & 28,09 & 26,82 & \\
\hline 'Rutgers' & 5,0 & 5,0 & 347.082 & 69,42 & \\
\hline
\end{tabular}

${ }^{1}$ Médias seguidas pela mesma letra minúscula na coluna não diferem entre si, pelo teste de Tukey, a 0,5\% de probabilidade. Dados transformados em $\sqrt{ } \mathrm{x}+0,5$. ${ }^{*} \mathrm{I}=$ Imune, $\mathrm{S}=$ Suscetível, $\mathrm{R}=$ Resistente 
2011). A cultivar 'Roxa' permitiu uma maior reprodução de $M$. enterolobii $(\mathrm{FR}=13,93)$, diferindo estatísticamente das outras cultivares, seguido pela alface 'Karla' $(\mathrm{FR}=$ 6,46). Segundo Pinheiro et al. (2003a), a resistência em alface é monogênica e dominante, e que embora o gene $M e$ tenha sido descrito, não se conhece o mecanismo de resistência (morfológico ou fisiológico).

Apesar de todas as espécies de pimentas e pimentões serem classificadas como suscetíveis, as mesmas podem ser separadas em três grupos. No primeiro grupo, as cultivares pimenta 'Dedo de Moça'( $C$. baccatum), 'Malagueta' ( $C$. frutescens), 'Doce Italiana' ( $C$. annuum) e 'Jalapeno M' ( $C$. annuum $)$ obtiveram $\mathrm{FR}$ mais baixos comparados às demais cultivares, com valores de FR de 1,$42 ; 5,19 ; 5,84$ e 6,73 , respectivamente. O segundo grupo, formado com o pimentão 'Dagmar' ( $C$. annuum), pimenta 'Amarela Comprida' (C. annuum), pimentão 'Casca Dura Ikeda' ( $C$. annuum), porta-enxerto para pimentão 'Silver' ( $C$. annuum), pimenão 'Magna Super' ( $C$. annuum) e pimenta 'Cambuci' ( $C$. baccatum), obteve FR intermediário de 11,$51 ; 15,14 ; 17,43 ; 17,93 ; 20,34$ e 22,48, respectivamente. E o terceiro grupo, com o porta enxerto para pimentão 'AF 8253' (C. annuum) que apresentou o maior fator de reprodução (FR = 47,94). Apesar da suscetibilidade em todas as plantas estudadas, notou-se níveis diferentes de reprodução dessa espécie a essas plantas. As informações obtidas concordam com os autores Melo et al. (2011), os quais relataram que a utilização do gene $N$, presente em pimentas e pimentões e que confere resistência às mesmas espécies do gene $M i$, seria pouco efetiva para promover níveis adequados de resistência de pimentões a $M$. enterolobii.

Pinheiro et al. (2013b) também constataram a suscetibilidade de oito genótipos de Capsicum estudados, com seis genótipos (BRS Garça, BRS Moema, BRS Mari, BRS Ema, BRS Sarakura e CNPH 148) que apresentaram um menor FR para $M$. enterolobii, variando de 1,42 a 2,4, comparado aos outros dois genótipos BRS Brasilândia e pimentão Tico que apresentaram FR elevado (29,58 e 22,22, respectivamente). Outro estudo também detectou níveis moderados de resistência a $M$. enterolobii em acessos de pimenta BGH-433 e BGH-4285, e de pimentão, PIM-031, PIX-022I-31-07-02 e PIX-022I-31-13-01. Esta informação é importante para a busca de fonte de resistência a $M$. enterolobii (MELO et al., 2011).

O conhecimento dos fatores de reprodução de $M$. enterolobii em plantas olerícolas ainda é pouco frequente na literatura, refletindo a importância de se estudar e caracterizar como plantas resistentes à respectiva espécie de nematoide. Essas plantas poderiam ser incluídas em programa de rotação de cultura, em locais onde seja difícil a implantação de outras culturas decorrente de alguns problemas enfrentados pelos produtores, dentre os quais a falta de interesse na comercialização de certos produtos agrícolas em determinadas regiões.

\section{Ensaio com plantas de adubação verde}

Entre as 18 plantas utilizadas como adubos verdes, apenas seis plantas indicadas na Tabela 3 foram suscetíveis a $M$. enterolobii. Assim, os adubos verdes que não multiplicaram a espécie $M$. enterolobii constituem opção viável para utilização na rotação de culturas em áreas infestadas por M. enterolobii.

No ensaio 06, as plantas de adubação verde inibiram a reprodução de $M$. enterolobii, obtendo-se assim, baixo fator de reprodução para azevém, mucuna cinza, mucuna preta, labe-labe e milheto, o que foi confirmado no segundo ensaio (Tabela 3). Com exceção do IG de 1,5 e o IMO de 1,0 obtidos em labe-labe, no segundo ensaio, todas as outras plantas estudadas frente a $M$. enterolobii apresentaram IG e IMO iguais a zero, em ambos os ensaios, verificando-se que o mecanismo de resistência (reação de hipersensibilidade) atua nesse grupo de plantas. Essa pequena variação é decorrente da variabilidade genética existente na composição dessas sementes, uma vez que pode existir a não homogeneidade na padronização das sementes, fato este que pode ocasionar resultados distintos do emprego dessas sementes para a diminuição da população das espécies de Meloidogyne. As plantas de ervilhaca, feijão de porco, guandu anão 'Iapar 43' e guandu 'Fava Larga', girassol 'Catissol' e girassol 'Uruguai comportam-se como suscetíveis a $M$. enterolobii, apresentando elevados FR. Com isso, pode-se verificar a imunidade da $C$. spectabilis, C. breviflora e a resistência da $C$. juncea, C. mucronata, C. ochroleuca, mucuna anã e nabo forrageiro. A suscetibilidade de guandu anão e a resistência de mucuna anã e nabo forrageiro a $M$. enterolobii, já haviam sido verificadas no ensaio 6 do estudo, sendo confirmadas também no ensaio 7.

Os resultados apontaram que $C$. juncea e $C$. spectabilis apresentaram baixo fator de reprodução de $M$. enterolobii, fato esse também observado em $C$. spectabilis por Guimarães, Moura e Pedrosa (2003). Entretanto, os mesmos autores verificaram que $C$. juncea foi suscetível a $M$. enterolobii, ocorrendo uma discordância de informações com o presente estudo, no qual foi constatado que a $C$. juncea inibiu a reprodução de $M$. enterolobii com $\mathrm{FR}=0,38$. Isto pode ser explicado pela variabilidade genética presente nas sementes comercializadas como adubação verde. 
Tabela 3 - Índice de galhas (IG), índice de massa de ovos (IMO), população final (PF) e fatores de reprodução (FR) de $M$. enterolobii em plantas de adubação verde

\begin{tabular}{|c|c|c|c|c|c|c|c|c|c|c|}
\hline & \multicolumn{4}{|c|}{$\mathrm{A}$} & \multicolumn{6}{|c|}{ B } \\
\hline Ensaio 06 & IG & IMO & $\overline{\mathrm{Pf}}$ & FR & Reação* & IG & IMO & $\mathrm{Pf}$ & FR & Reação* \\
\hline Azevém & 0,0 & 0,0 & $228 \mathrm{a}$ & $0,05 \mathrm{a}$ & $\mathrm{R}$ & 0,0 & 0,0 & $205 \mathrm{a}$ & $0,04 \mathrm{a}$ & $\mathrm{R}$ \\
\hline Mucuna preta & 0,0 & 0,0 & $315 \mathrm{a}$ & $0,06 \mathrm{a}$ & $\mathrm{R}$ & 0,0 & 0,0 & $242 \mathrm{a}$ & $0,05 \mathrm{a}$ & $\mathrm{R}$ \\
\hline Mucuna cinza & 0,0 & 0,0 & $304 \mathrm{a}$ & $0,06 \mathrm{a}$ & $\mathrm{R}$ & 0,0 & 0,0 & $255 \mathrm{a}$ & $0,05 \mathrm{a}$ & $\mathrm{R}$ \\
\hline Labe-labe & 0,0 & 0,0 & $448 \mathrm{a}$ & $0,09 \mathrm{a}$ & $\mathrm{R}$ & 1,5 & 1,0 & $1.778 \mathrm{a}$ & $0,36 \mathrm{~b}$ & $\mathrm{R}$ \\
\hline Milheto & 0,0 & 0,0 & 718 a & $0,14 \mathrm{a}$ & $\mathrm{R}$ & 0,0 & 0,0 & $620 \mathrm{a}$ & $0,12 \mathrm{ab}$ & $\mathrm{R}$ \\
\hline CV (\%) & & & 46,62 & 5,80 & & & & 73,82 & 12,18 & \\
\hline 'Rutgers' & 5,0 & 5,0 & 299.559 & 59,91 & & 5,0 & 4,8 & 293.087 & 58,62 & \\
\hline Ensaio 07 & & & $\mathrm{~A}$ & & & & & $\mathrm{~B}$ & & \\
\hline Mucuna anã & 0,0 & 0,0 & $315 \mathrm{a}$ & $0,06 \mathrm{a}$ & $\mathrm{R}$ & 0,0 & 0,0 & $113 \mathrm{a}$ & $0,02 \mathrm{a}$ & $\mathrm{R}$ \\
\hline Nabo forrageiro & 2,2 & 0,8 & $573 \mathrm{a}$ & $0,11 \mathrm{a}$ & $\mathrm{R}$ & 1,7 & 0,8 & $395 \mathrm{a}$ & $0,08 \mathrm{a}$ & $\mathrm{R}$ \\
\hline Ervilhaca & 3,2 & 3,2 & $14.495 \mathrm{~b}$ & $2,90 \mathrm{~b}$ & S & 3,8 & 3,0 & $13.891 \mathrm{~b}$ & $2,78 \mathrm{~b}$ & S \\
\hline Feijão de porco & 4,7 & 4,7 & $34.492 \mathrm{c}$ & $6,90 \mathrm{c}$ & S & 5,0 & 5,0 & $39.577 \mathrm{c}$ & $7,92 \mathrm{c}$ & S \\
\hline Guandu anão cv. 'Iapar 43' & 4,8 & 4,7 & $62.653 \mathrm{~d}$ & $12,53 \mathrm{~d}$ & $S$ & 4,8 & 4,7 & $53.887 \mathrm{c}$ & $10,78 \mathrm{c}$ & S \\
\hline Guandu cv. 'Fava Larga' & 5,0 & 5,0 & $77.797 \mathrm{~d}$ & $15,56 \mathrm{~d}$ & $S$ & 5,0 & 5,0 & $184.573 \mathrm{~d}$ & $36,91 \mathrm{~d}$ & S \\
\hline $\mathrm{CV}(\%)$ & & & 20,40 & 17,94 & & & & 14,78 & 13,17 & \\
\hline 'Rutgers' & 5,0 & 5,0 & 358.505 & 71,70 & & 5,0 & 5,0 & 284.191 & 56,84 & \\
\hline \multicolumn{11}{|l|}{ Ensaio 08} \\
\hline Crotalaria spectabilis & 0,2 & 0,0 & $0 \mathrm{a}$ & $0,00 \mathrm{a}$ & I & - & - & - & - & - \\
\hline Crotalaria breviflora & 0,0 & 0,0 & $0 \mathrm{a}$ & $0,00 \mathrm{a}$ & I & - & - & - & - & - \\
\hline Mucuna anã & 0,0 & 0,0 & $40 \mathrm{a}$ & $0,01 \mathrm{a}$ & $\mathrm{R}$ & - & - & - & - & - \\
\hline Crotalaria mucronata & 2,3 & 0,8 & $642 \mathrm{a}$ & $0,13 \mathrm{a}$ & $\mathrm{R}$ & - & - & - & - & - \\
\hline Crotalaria ochroleuca & 2,3 & 0,8 & $1.473 \mathrm{a}$ & $0,29 \mathrm{ab}$ & $\mathrm{R}$ & - & - & - & - & - \\
\hline Nabo forrageiro & 1,5 & 1,5 & $1.485 \mathrm{a}$ & $0,30 \mathrm{ab}$ & $\mathrm{R}$ & - & - & - & - & - \\
\hline Crotalaria juncea & 2,5 & 1,5 & $1.877 \mathrm{a}$ & $0,38 \mathrm{ab}$ & $\mathrm{R}$ & - & - & - & - & - \\
\hline Girassol cv. 'Catissol' & 3,3 & 3,2 & $14.237 \mathrm{~b}$ & $2,85 \mathrm{~b}$ & $S$ & - & - & - & - & - \\
\hline Girassol cv. 'IAC Uruguai' & 5,0 & 5,0 & $60.605 \mathrm{c}$ & $12,12 \mathrm{c}$ & $S$ & - & - & - & - & - \\
\hline Guandu anão cv. 'Iapar 43' & 4,8 & 4,8 & $71.353 \mathrm{c}$ & $14,27 \mathrm{c}$ & $S$ & - & - & - & - & - \\
\hline $\mathrm{CV}(\%)$ & & & 46,99 & 32,16 & & & & & & \\
\hline 'Rutgers' & 5,0 & 5,0 & 313.527 & 62,71 & & - & - & - & - & - \\
\hline
\end{tabular}

${ }^{1}$ Médias seguidas pela mesma letra minúscula na coluna não diferem entre si, pelo teste de Tukey, a 0,5\% de probabilidade. Dados transformados em $\sqrt{x}+0,5$. "I = Imune, $\mathrm{S}=$ Suscetível, $\mathrm{R}=$ Resistente

Em todos os ensaios, o padrão de suscetibilidade tomate 'Rutgers' proporcionou elevado FR, comprovando a viabilidade dos inóculos de $M$. enterolobii.

Notoriamente, observou-se que as espécies vegetais utilizadas como adubação verde, apresentaram bons resultados no controle de $M$. enterolobii, contribuindo para a diminuição dessa espécie.
Desta forma, o conhecimento da hospedabilidade das plantas de olerícolas e adubação verde a M. enterolobii, podem contribuir para a melhor compreensão das relações nematoides - plantas, e que apesar da alta virulência dessa espécie, o seu círculo de hospedeiros não é tão amplo como o esperado. Entretanto, nessa pesquisa, foram encontrados muitos cultivares de olerícolas e plantas utilizadas como 
adubos verdes resistentes, que podem ser boas opções para a rotação de culturas em áreas infestadas com $M$. enterolobii.

\section{CONCLUSÕES}

1. Todas as cultivares de brássicas estudadas; a alface 'Grand Rapids'; cebolinhas 'Tokyo' e 'Nebuka'; alho 'Poró Gigante'; salsas 'Comum HT' e 'Graúda Portuguesa'; cenouras 'Brasília', 'Brasília Irecê' e 'Planeta'; e os adubos verdes Crotalaria spectabilis, C. breviflora; C. mucronata, C. ochroleuca, C. juncea; azevém; labe-labe; milheto, mucuna anã, mucuna cinza, mucuna preta e nabo forrageiro são considerados resistentes a $M$. enterolobii, sendo possíveis fontes de resistência a essa espécie;

2. As plantas resistentes são opções adequadas para a inclusão na rotação de culturas em áreas infestadas com M. enterolobii.

\section{AGRADECIMENTOS}

À empresa Piraí Sementes, pelo fornecimento das sementes utilizadas na pesquisa; à Fundação de Amparo à Pesquisa do Estado de São Paulo (FAPESP), pelo suporte financeiro e à Coordenação de Aperfeiçoamento de Pessoal de Nível Superior (CAPES), pela bolsa de estudo concedida à primeira autora.

\section{REFERÊNCIAS}

BITENCOURT, N. V.; SILVA, G. S. Reprodução de Meloidogyne enterolobii em olerícolas. Nematologia Brasileira, v. 34, p. 181 $183,2010$.

BRITO, J. A. et al. Effects of the Mi-1, $N$ and Tabasco genes on infection and reproduction of Meloidogyne mayaguensis on tomato and pepper genotypes. Journal of Nematology, v. 39, n. 4, p. 327-332, 2007.

CANTU, R. R. et al. Reação de porta enxertos comerciais de tomateiros a Meloidogyne mayaguensis. Summa Phytopathologica, v. 35, n. 3, p. 216-218, 2009.

CARNEIRO, R. M. D. G. et al. Primeiro registro de Meloidogyne mayaguensis em goiabeira no Brasil. Nematologia Brasileira, v. 25 , p. $223-228,2001$.

CARNEIRO, R. M. D. G. et al. Primeiro registro de Meloidogyne mayaguensis parasitando plantas de tomate $\mathrm{e}$ pimentão resistentes meloidoginose no estado de São Paulo. Nematologia Brasileira, v. 30, n. 1, p. 81-86, 2006.
CHARCHAR, J. M. et al. Efeito de rotação de culturas no controle de Meloidogyne spp. em cenoura na região norte do Estado de Minas Gerais. Nematologia Brasileira, v. 31, p. 173$179,2007$.

COOLEN, W. A.; D'HERDE, C. J. A method for quantitative extration of nematodes from plant tissue. Ghent: Nematology and Entomology Reseach Station, 1972. 77 p.

EUROPEAN AND MEDITERRANEAN PLANT PROTECTION ORGANIZATION. An Emerging Root - knot Nematode, Meloidogyne enterolobii: Addition to the EPPO Alert List. Paris: EPPO, 2008. 26 p. (Reporting Service, 5).

FERREIRA, D. F. Sisvar: a computer statistical analysis system. Ciência e Agrotecnologia, v. 35, n. 6, p. 1039-1042, 2011.

GUIMARÃES, L. M. P.; MOURA, R. M.; PEDROSA, E. M. R. Parasitismo de Meloidogyne mayaguensis em diferentes espécies botânicas. Nematologia Brasileira, v. 27, p. 139-145, 2003.

INOMOTO, M. M. et al. Reação de seis adubos verdes a Meloidogyne javanica e Pratylenchus brachyurus. Nematologia Brasileira, v. 30, n. 1, p. 39-44, 2006.

JENKINS, W. R. A. A rapid centrifugal-flotation technique for separating nematodes from soil. Plant Disease Report, v. 48, p. $692,1964$.

KIEWNICK, S.; DESSIMOZ, M.; FRANCK, L. Effects of the $M i-1$ and the $N$ root - knot nematode - resistance gene on infection and reproduction of Meloidogyne enterolobii on tomato and pepper cultivars. Journal of Nematology, v. 41, n. 2, p. 134$139,2009$.

MELO, O. D. et al. Triagem de genótipos de hortaliças para resistência a Meloidogyne enterolobii. Pesquisa Agropecuária Brasileira, v. 46, n. 8, p. 829-835, 2011.

MIRANDA, G. B. et al. Avaliação de acessos de Psidium spp. quanto à resistência a Meloidogyne enterolobii. Bragantia, v. 71, n. 1, p. 52-58, 2012.

MORAES, S. R. G. et al. Influência de leguminosas no controle de fitonematoides no cultivo orgânico de alface americana e de repolho. Fitopatologia Brasileira, v. 31, n. 2, p. 188-191, 2006.

OOSTENBRINK, M. Major characteristics of the relation between nematodes and plants. Mededelingen Landbouwhogeschool, v. 66, p. 1-46, 1966.

PINHEIRO, J. B. et al. Manejo de nematoides na cultura da alface. Brasília: Embrapa, 2013a. 8 p. (Circular Técnica, 124).

PINHEIRO, J. B. et al. Reprodução de Meloidogyne spp. em Capsicum spp. Nematologia Brasileira, v. 37, p. 20-25, 2013 b.

RAMMAH, A.; HIRSCHMANN, H. Meloidogyne mayaguensis n. sp. (Meloidogynidae), a root-knot nematode from Puerto Rico. Journal of Nematology. v. 20, n. 1, p. 58-69, 1988.

RODRIGUEZ, M. G.; GÓMEZ, L.; PETEIRA, B. Meloidogyne mayaguensis Rammah y Hirschmann, plaga emergente para la agricultura tropical y subtropical. Revista Protección Vegetal, v. 22, n. 3, p. 183-196, 2007. 
RODRIGUEZ, M. G.; SANCHEZ, L.; ROWE, J. Host status of agriculturally important plant families to the root-knot nematode Meloidogyne mayaguensis. Nematropica, v. 33, n. 2, p. 125130, 2003.

ROSA, J. M. O.; WESTERICH, J. N.; WILCKEN, S. R. S. Reação de genótipos e híbridos de tomateiro à Meloidogyne enterolobii. Ciência Rural, v. 44, n. 7, p. 1166-1171, 2014.

ROSA, J. M. O.; WESTERICH, J. N.; WILCKEN, S. R. S. Reação de híbridos e cultivares de milho a Meloidogyne enterolobii e $M$. javanica. Nematologia Brasileira, v. 36, p. 10-14, 2012.

ROSA, J. M. O.; WESTERICH, J. N.; WILCKEN, S. R. S. Reprodução de Meloidogyne javanica em olerícolas e em plantas utilizadas na adubação verde. Tropical Plant Pathology, v. 38, n. 2, p. 133-141, 2013.

SILVA, G. S. Métodos alternativos de controle de fitonematoides. Tropical Plant Pathology, v. 35, p. CXI, 2010. Suplemento.

TAYLOR, A. L.; SASSER, J. N. Biology, identification and control of root-knot nematodes (Meloidogyne sp.). Raleigh: North Carolina State University Graphics, 1978. 111 p.
TIGANO, M. et al. Genetic diversity of the root-knot nematode Meloidogyne enterolobii and development of a SCAR marker for this guava-damaging species. Plant Pathology, v. 59, n. 6, p. 1054-1061, 2010.

WESTERICH, J. N.; ROSA, J. M. O.; WILCKEN, S. R. S. Estudo comparativo da biologia de Meloidogyne enterolobii ( $M$. mayaguensis) e Meloidogyne javanica em tomateiros com gene Mi. Summa Phytopathologica, v. 37, n. 1, p. 35-41, 2011.

WILCKEN, S. R. S. et al. Reproduction of Meloidogyne enterolobii in rootstocks and cucumber hybrids. Horticultura Brasileira, v. 31, n. 4, p. 618-621, 2013.

XU, J. et al. Characterisation of Meloidogyne species from China using isozyme phenotypes and amplified mitochondrial DNA restriction fragment length polymorphism. European Journal of Plant Pathology, v. 110, n. 3, p. 309-315, 2004.

YANG, B.; EISENBACK, J. D. Meloidogyne enterolobii n. sp. (Meloidogynidae), a root-knot nematode parasitising pacara earpod tree in China. Journal of Nematology, v. 15, n. 3, p. 381-391, 1983. 